Archived version from NCDOCKS Institutional Repository http://libres.uncg.edu/ir/asu/

\title{
Appalachľan
}

B O O N E, N O R T H C A R O L I N A

\section{The Work Organization Of Long-Haul Truck Drivers And The Association With Body Mass Index}

\author{
By: Adam Hege, PhD, Yorghos Apostolopoulos, PhD, Mike Perko, PhD, \\ Sevil Sonmez, PhD, and Robert Strack, PhD
}

\begin{abstract}
Objective: The aim of this study was to examine relationships between work organization features of work hours, work schedules, and job stress with body mass indexes (BMls) of long-haul truck drivers. Methods: Face-to-face survey data were collected first, followed by collection of anthropometric measures including height and weight (n $1 / 4$ 260). Logistic regression (backward stepwise model) was used to identify significant predictors of BMI and to analyze odds ratios. Results: Mean BMI was $33.40 \mathrm{~kg} / \mathrm{m} 2$, with $64.2 \%$ obese $(B M I>30 \mathrm{~kg} / \mathrm{m} 2$ ) and $18.4 \%$ extreme/morbidly obese (BMI $>40 \mathrm{~kg} / \mathrm{m} 2)$. Working more than 11 daily hours was associated with statistically significant increased odds for being extreme obese. Conclusion: Findings suggest that longer work hours (> 11 hours daily) have a major influence on odds for obesity among this population. The results align with recent NIOSH calls for integrated approaches to worker health.
\end{abstract}

Hege, Adam PhD; Apostolopoulos, Yorghos PhD; Perko, Mike PhD; Sönmez, Sevil PhD; Strack, Robert PhD. (2016). The Work Organization of Long-Haul Truck Drivers and the Association With Body Mass Index. Journal of Occupational and Environmental Medicine, 58(7), 712-717. doi: 10.1097/JOM.0000000000000734. Publisher version of record available at: https://journals.Iww.com/joem/Fulltext/2016/07000/

The_Work_Organization_of_Long_Haul_Truck_Drivers.10.aspx 


\title{
The Work Organization of Long-Haul Truck Drivers and the Association With Body Mass Index
}

\author{
Adam Hege, PhD, Yorghos Apostolopoulos, PhD, Mike Perko, PhD, Sevil Sönmez, PhD, \\ and Robert Strack, PhD
}

\begin{abstract}
Objective: The aim of this study was to examine relationships between work organization features of work hours, work schedules, and job stress with body mass indexes (BMIs) of long-haul truck drivers. Methods: Face-toface survey data were collected first, followed by collection of anthropometric measures including height and weight $(n=260)$. Logistic regression (backward stepwise model) was used to identify significant predictors of BMI and to analyze odds ratios. Results: Mean BMI was $33.40 \mathrm{~kg} / \mathrm{m}^{2}$, with $64.2 \%$ obese (BMI $>30 \mathrm{~kg} / \mathrm{m}^{2}$ ) and $18.4 \%$ extreme/morbidly obese (BMI $>40 \mathrm{~kg} / \mathrm{m}^{2}$ ). Working more than 11 daily hours was associated with statistically significant increased odds for being extreme obese. Conclusion: Findings suggest that longer work hours ( $>11$ hours daily) have a major influence on odds for obesity among this population. The results align with recent NIOSH calls for integrated approaches to worker health.
\end{abstract}

$\mathrm{T}$ he globalization of markets, technological advances, deregulation of industries, and declines in union membership beginning in the early 1980s have all been deemed responsible for changes in work organization (longer work hours, irregular work schedules, and increased job stress) globally and are a major contributor to occu-

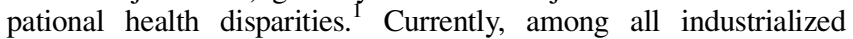
nations, the U.S. has the longest working hours on a yearly basis, while the proportion of workers working long hours has increased substantially over the past three decades. ${ }^{2,3}$ Findings from the 2010 National Health Interview Survey showed that $18.7 \%$ of American workers work 48 or more hours per week and $7.2 \%$ Americans reported working 60 or more hours per week. ${ }^{4}$ In addition, the 2010 National Health Interview Survey revealed that $28.7 \%$ of American workers reported working alternative or rotating shifts, or periods outside the time period of 7 a.m. to 6 p.m., ${ }^{5-7}$ up from the $17.7 \%$ found in 2004 by the Bureau of Labor Statistics. ${ }^{4}$ Although long work hours and shift work are prevalent, job stress, or the imbalance between the physical and psychological demands and the inability to cope with or control situations affecting one's work, has also risen. ${ }^{8}$ Job demands including a fast work pace, time pressures, having to learn new things, and repetitive work ${ }^{9}$ are rampant, whereas previous research has suggested that factors such as social isolation on the job or lack of support from coworkers and supervisors may increase psychosocial job stress. ${ }^{8}$

From the Appalachian State University, Department of Health and Exercise Science, Boone, North Carolina (Dr Hege); Texas A\&M University, Department of Health and Kinesiology, College Station (Dr Apostolopoulos); University of North Carolina at Greensboro, Department of Public Health Education (Drs Perko, Strack); and Central Florida University, Department of Tourism, Events \& Attractions, Orlando (Dr Sönmez).

This paper is part of a commercial driver sleep study conducted with research funds awarded to Yorghos Apostolopoulos by the University of North Carolina-Greensboro's (UNCG) Office of Research and Economic Development. Additional funds were provided by UNCG's School of Health and Human Sciences, Bryan School of Business and Economics, Department of Public Health Education, and Department of Kinesiology.

Authors report no conflict of interest or financial disclosures.

Address correspondence to: Adam Hege, PhD, Assistant Professor, Appalachian State University, Beaver College of Health Sciences, Department of Health and Exercise Science, Holmes Convocation Center, 111 Rivers Street, Boone, NC 28608 (hegeba@appstate.edu).
Compared with all U.S. workers, long-haul truck drivers have among the highest rates of long work hours and schedules characterized as shift work, and the two work organization factors are also closely linked to many of the job stressors that they face. Specifically, data from the 2010 Occupational Health Supplement of the National Health Interview Survey revealed that the prevalence of drivers/sales workers and truck drivers working 48 or more hours per week was $47.2 \%$, while $45.8 \%$ of drivers/sales workers and truck drivers reported working nonstandard shifts. ${ }^{10}$ The work organization of long-haul truck drivers is substantially influenced by the Department of Transportation's (DOT) hours of service (HOS) regulations allowing up to 14 hours of work per day (11 hours of driving time), corporate operations emphasizing profit and productivity, and the competitive culture found within the industry. ${ }^{11}$ As a result, drivers experience time pressures due to tightrunning delivery schedules imposed by dispatchers (their supervisor) and little control over conditions influencing their work. ${ }^{11}$ They further perform the majority of their job duties individually, including driving many miles, with limited social connection, and have been considered a lone worker population. ${ }^{12}$

Epidemiological evidence suggests that the work environment of long-haul truck drivers has a negative influence on the both the behaviors and health outcomes of the occupational population. ${ }^{12}$ Helmkamp et al ${ }^{13}$ compared the super sector of transportation, warehousing, and utilities (TWU) professions, of which long-haul truck drivers are a part of, to all U.S. workers, and found that the rates of smoking ( $25.6 \%$ vs $23.8 \%)$, drinking $(72.2 \%$ vs $70.2 \%$ ), overweight/obese ( $68.3 \%$ vs $59.3 \%$ ), and physical inactivity $(66.7 \%$ vs $65.9 \%)$ were all greater among the TWU sector. The TWU sector also had greater rates of yearly mean lost workdays due to health (4.9\% vs $3.9 \%$ ), hypertension ( $20.0 \%$ vs $17.7 \%)$, and diabetes $(4.4 \%$ vs $3.9 \%)$. Not surprisingly, the profession is classified as one of the riskiest occupations, with higher morbidity rates and a decreased life expectancy when compared with the general population. ${ }^{11,14-16}$

Obesity, defined as a BMI of $30 \mathrm{~kg} / \mathrm{m}^{2}$ or greater, is linked to these work organization features (long work hour, shift work, job stress), and affects certain occupations more than others. ${ }^{17-19}$ Specific to long-haul truck drivers, a recent survey from the National Institute of Occupational Safety and Health (NIOSH) found that nearly $70 \%$ of U.S. long-haul truck drivers were obese, more than double the rate of American workers, and $17 \%$ were extreme or morbidly obese, which increases the risk for cardiometabolic disease. ${ }^{20}$ In the aforementioned survey of current U.S. truck drivers, heart disease prevalence was actually less than the general population according to 2010 NHIS data ( $4.4 \%$ vs $6.7 \%)$, but drivers had a higher prevalence of hypertension $(26.3 \%$ vs $24.1 \%)$ and more than double the prevalence rate of diabetes $(14.4 \%$ to $6.8 \%){ }^{20}$ Regarding lower heart disease prevalence, Birdsey et $\mathrm{al}^{21}$ used prevalence data in a mortality study of long-haul drivers, and their results led them to suggest two potential reasons for the difference: a "healthy worker effect" and the notion that workers are typically healthier than the general population, or that it could come as a result of the extensive medical qualifications needed to operate a commercial motor vehicle. Further, in their examination of U.S truck drivers and heart disease, Robinson and Burnett ${ }^{22}$ also used 
mortality data and found that the greatest risks for drivers dying from heart disease was for those under the age of 55 and suggested that researchers should examine occupational exposures such as long work hours, shiftwork, and job stress as potential contributors to the development of heart disease such as overweight/obese.

With obesity being a complex health challenge ${ }^{23}$ linked to numerous occupational safety and health risks ${ }^{24}$ and individual level behavior change strategies having little impact on long-haul truck drivers at the population level, ${ }^{25}$ recent research has suggested that the work conditions experienced by long-haul truck drivers warrant further attention concerning the possible contribution to the high obesity prevalence. ${ }^{11}$ For example, a recent study in Italy found that one of the highest predictive factors of obesity among Italian truck drivers was working long hours and driving for long periods of time. ${ }^{26}$ Therefore, it is critical to further understand how the work organization of U.S. long-haul truck drivers serves as a mechanism for exacerbating an already "obesogenic" environment in terms of individual level behavior mechanisms (physical activity and diet). ${ }^{27-30}$ Therefore, the purpose of this study was to examine the relationship between the work organization features of work hours, work schedules, and job stress with the BMIs of long haul truck drivers. Specific understanding of these interactions may inform both prevention programming in long-haul trucking companies and public policy enacted at the federal level in relation to the industry.

\section{METHODS}

A nonexperimental descriptive, cross-sectional design was employed to collect survey and anthropometric data from 260 long-haul truck drivers at a major truckstop in central North Carolina from October 2012 until March 2013. Long-haul truckers first completed a face-to-face survey with a researcher, and the survey was followed up with the collection of numerous objective anthropometric measures. This particular study focuses on height and weight measures, which led to the calculation of BMIs of the driver sample.

Permission to collect data was granted by the corporate office of the national truckstop. Using intercept techniques, researchers approached drivers and asked several screening questions to determine eligibility for inclusion in the study. To be enrolled, drivers were required to be long-haul truckers planning to spend the night at the truck stop where data collection took place. From approximately 360 drivers approached for potential inclusion, 260 met the criteria and were included. Truckers not meeting the criteria were either short-haul or regional drivers or not spending the night at the truckstop. Informed consent was collected from participants. The study and data collection were approved by the Institutional Review Board (IRB) of the University of North Carolina at Greensboro and the data for this study was originally analyzed in May 2015.

\section{Survey Data}

\section{Work Hours}

Work hours were measured by asking drivers, "how many hours of work do you average daily including both driving and other duties?" Response selections included less than 6 hours, between 6 and 7 hours, between 7 and 8 hours, between 8 and 9 hours, between 9 and 10 hours, 10 to 11 hours, 11 to 12 hours, 12 to 13 hours, 13 to 14 hours, over 14 hours. On the basis of DOT regulations ${ }^{31}$ and the high number of hours that drivers accumulate (ie, only three drivers in our sample worked eight or less hours per day), the number of hours was further categorized in this manner: 11 hours or less and 11 or more hours.

\section{Work Schedules}

To measure participant's experiences with rotating work schedules, the following two questions were asked: "Is your daily work schedule the same each day?" and "Do you work the same number of hours daily?" The response selections were "same" or "different." Drivers were then asked about perception of their delivery schedules. Supervisors schedule delivery times and monitor drivers' driving time. Specifically, the following question was asked: "How often do you consider your delivery schedule to be realistic?" The response selections included never, rarely, sometimes, frequently, and always. For analysis, the variable was categorized: "never, rarely, or sometimes" as "unrealistic" and "frequently or always" as "realistic."

\section{Job Stress}

Six questions were asked regarding stress job stress. Participants were asked about the frequency of a fast work pace, time pressures, repetitive work, learning new things, supervisor support, and coworker support. The response selections were never, rarely, sometimes, frequently, and always. For analysis, the variables were categorized: "never, rarely, or sometimes" as "low" and "frequently or always" as "increased." A seventh question asked drivers about their perceived job stress. Response selections included no stress, mild stress, moderate stress, high stress, very high stress, chronic stress. For analysis, "no, mild, or moderate stress" became "low stress" and "high, very high, and chronic" became "elevated stress."

\section{Potential Confounders}

On the basis of the literature, ${ }^{17}$ there is the recognition that individual-level factors could affect the relationship between work hours, schedules, and job stress and BMI and were therefore treated as potential confounders. Specific confounding measures for this study included driver age and years of experience in the profession. With increasing age and years of experience, one could expect the driver would be able to better adapt to the work conditions and manage his health behaviors and stress level. Conversely, chronic stress could affect the body physiologically over time and with years of driving experience. For analysis, driver age was categorized: "45 years old or younger" and "46 years old or older." Years of driving experience was categorized: "10 or less years" and "more than 10 years."

\section{Anthropometric Data}

\section{Body Mass Index (BMI)}

BMI was the primary outcome for this study. Using a privacy screen in a low traffic area of the truck stop, the weight of each truck driver was recorded in $\mathrm{kg}$ to the nearest $0.1 \mathrm{~kg}$ with shoes off using an Elite XXL scale. Height was measured to the nearest $\mathrm{cm}$ using a portable stadiometer (Seca, Chino, CA). BMI $\left(\mathrm{kg} / \mathrm{m}^{2}\right)$ was calculated and rounded to one decimal. We used the height and weight measures to calculate BMI by using the following formula: (weight in pounds $X 703$ )/(height in inches ${ }^{2}$ ). BMI was categorized using criteria established by the National Heart, Lung, and Blood Institute: $<24.99$ "Normal"; 25 to 29.99 "Overweight"; 30 to 39.99 "Obese"; $>40$ "Extreme Obese." 32

\section{Statistical Analyses}

Descriptive statistics were computed to provide a profile of the characteristics of the truck driver sample, including BMI categorization, work organization characteristic, and age and years of driving experience. Multiple logistic regression modeling was used to identify significant predictors of BMI category and to analyze the odds ratios (ORs) from the predictor variables. We first used a model that featured all of the work organization factors and the potential confounding variables to assess the fit. The first model was not statistically significant $(P=0.28)$. Using the findings from the first model, we used backward stepwise regression in which variables that had a $P$ value less than 0.40 were included in 
the stepwise terms for the second model. ${ }^{33}$ Variables that were included in the backward stepwise terms included work hours (more than 11 hours), work pace (high frequency of fast pace), repetitive work (high frequency), coworker support (low level), and age (45 years and younger vs 46 years and older). All statistical analyses were conducted using SPSS 23.00 (IBM Corp, Armonk, NY). ${ }^{34}$

\section{RESULTS}

The mean age was 46.63 years of age $(58.1 \% 46$ years or older) and the mean years of driving experience $(62.7 \% 11$ or more years) was 14.97 years. The mean BMI was $33.40 \mathrm{~kg} / \mathrm{m}^{2}$, with $64.2 \%$ being obese and $18.4 \%$ being characterized as extreme or morbidly obese. Seventy percent averaged working more than 11 hours daily, $82.7 \%$ worked irregular daily schedules, $63.8 \%$ worked irregular hours daily, and $36.9 \%$ considered their delivery schedules to be unrealistic. Regarding job stress, $46.2 \%$ reported a faster work pace, $51.2 \%$ faced increased time pressures, $81.9 \%$ had high levels of repetitive work, $40.4 \%$ frequently had to learn new things, $27.3 \%$ had low supervisor support, $64.2 \%$ had low coworker support, but only $22.3 \%$ actually considered their job highly stressful.

The first logistic regression model with all of the work organization factors and confounder variables was not statistically significant $(P=0.28)$. Using backward stepwise regression modeling, we eliminated variables not contributing substantially to the model $(P>0.40)$ to construct a second model; the variables with $(P<0.40)$ in the first model included work hours $\left(X^{2}=11.00\right.$, $P=0.01)$, pace of work $\left(X^{2}=3.42, P=0.33\right)$, repetitive work $\left(X^{2}=4.06, P=0.26\right)$, coworker support $\left(X^{2}=6.40, P=0.09\right)$, and age category $\left(X^{2}=9.60, P=0.02\right)$. The second model limited to these variables was significant $(P<0.01)$, and the measure of $\mathrm{R}^{2}$ (Nagelkerke) remained relatively moderate $(0.11)$. From the backward stepwise regression, the only two remaining statistically significant predictors to the model included working more than 11 hours $\left(X^{2}=11.06, P=0.01\right)$ and an age of 45 years or younger $\left(X^{2}=12.25, P=0.01\right)$. A faster work pace $\left(X^{2}=2.05, P=0.56\right)$, higher repetitive work $\left(X^{2}=4.20, P=0.24\right)$, and lower coworker support $\left(X^{2}=5.75, P=0.13\right)$ remained statistically insignificant in the second model.

When exploring the associated ORs, we only examined the two statistically significant variables to the model (working more than 11 hours and an age of 45 years or younger). With healthy BMI as the reference category, working more than 11 hours had increased odds [OR 4.53, confidence interval (CI) 1.34 to 115.31, $P<0.01$ ] for being extreme obese. Being 45 years of age and younger also held increased odds (OR 4.48, CI 1.37 to $14.67, P<0.01$ ) for being extreme obese when compared with the healthy/normal category. With the CIs both being over one for both, we can imply that there was a positive association. This in effect means that truckers in our sample had odds of $353 \%$ greater of being extreme obese if working more than 11 hours and $348 \%$ greater odds if 45 years of age or younger. With extreme obesity being a significant problem in our sample (18.4\%), we further made comparisons using the overweight categories and obese categories as references to examine comparisons with the extreme obese category. We found that, when using the overweight category as a reference, with 11 hours or more of work daily, the OR was 1.88 (CI 0.70 to 5.19), implying no association with the CI's covering one. However, we again found a positive association with the age of 45 years and younger (OR 4.04, CI 1.68 to $9.71, P<0.01$ ) when compared with the overweight category. Therefore, we could imply that this means that there was a $304 \%$ greater odds in being extremely obese among those drivers aged 45 years and younger than the overweight category. Last, working more than 11 hours (OR 3.46 , CI 1.43 to $8.38, P<0.01$ ) and being 45 years or younger (OR 2.72, CI 1.26 to $5.86, P<0.05$ ) had increased odds for being extreme obese when compared with the obese category. With the CIs being above one, we could classify this as a positive association. Specifically, when compared with the obese category, the odds of being extreme obese were $246 \%$ greater for those working more than 11 hours, whereas the odds were $172 \%$ greater for those aged 45 years or younger of being extreme obese when compared with the obese category (Tables 1-3).

\section{DISCUSSION}

Findings from this study suggest that working long hours may be the most critical work organization feature to long-haul truckers. Specifically, working more than 11 hours daily was associated with statistically significant increased odds for being extreme obese when compared with the obese category and the health category. These associations persisted after adjustments for other job stressors, driver age, and years of experience. Consistent with the literature, the findings insinuate that long work hours could influence drivers' body physiologically and their health behavior (physical inactivity and poor nutritional intake). ${ }^{1}$ The findings also

TABLE 1. Trucker Profile $(N=260)$

$N$

Body mass index $(\mathrm{BMI}):($ Mean $=33.40)$

Healthy (24.99 or less)

Overweight (25-29.99)

Obese (30-39.99)

Extremely obese (40 or greater)

66

119

Work organization variables

Work hours

11 hours or less

More than 11 hours

78

Daily schedule

Same each day

Different each day

48

Daily hours

Same each day

Different each day

Delivery schedule

Unrealistic

Realistic

Work pace

Slower

Faster

Time pressure

Lower

Higher

Repetitive work

Lower

Higher

Learn new things

Less often

More often

182

45

215

94

166

Supervisor support

Low

High

Coworker support

Low

High

Perceived stress

Low

High

Potential confounders

Driving experience $($ Mean $=14.97$ years $)$ 
TABLE 2. Variables Included in the Second Logistic Regression Model

\begin{tabular}{lrc}
\hline Effect & $\boldsymbol{X}^{\mathbf{2}}$ & $\boldsymbol{P}$ \\
\hline Working more than 11 hours & 11.06 & 0.01 \\
Faster work pace & 2.05 & 0.56 \\
High repetitive work & 4.20 & 0.24 \\
Low coworker support & 5.75 & 0.13 \\
45 years and younger & 12.25 & 0.01 \\
\hline
\end{tabular}

concur with the review by Soloveiva et al, ${ }^{17}$ which concluded that longer work hours were the most critical aspect of work organization to weight gain and obesity among men. Critically, longer hours of work could allow for less time to exercise and obtain physical activity, particularly in sedentary jobs such as truck driving, and less time to prepare and consume healthier food options. ${ }^{2,35}$ Chronic stress from repeated long hour days has been shown to alter health behaviors through hormone imbalances, namely leptin. ${ }^{36,37}$ Long work hours have also been associated with sleep deprivation among long-haul truck drivers, ${ }^{38}$ which can impact the body physiologically, specifically cortisol levels, and create abnormal stress responses. ${ }^{3}$ Prolonged sleep deprivation and sleep disorders can potentially lead to detrimental effects on the body's endocrine system and metabolic rate. ${ }^{2,5}$ In fact, several studies have indicated that the linkage between longer work hours and obesity is mediated by shorter sleep duration. ${ }^{39-41}$ Interestingly, the younger drivers in our sample had higher odds for being overweight, obese, or extreme

$\overline{\text { TABLE 3. Odds Ratios From Second Logistic Regression }}$ Model $^{*}$

\begin{tabular}{|c|c|c|c|c|c|}
\hline \multirow{2}{*}{$\begin{array}{l}\text { Selected Category vs } \\
\text { Reference } \\
\text { Overweight vs } \\
\text { Healthy }\end{array}$} & \multirow[b]{2}{*}{ B (SE) } & \multirow[b]{2}{*}{ Wald } & \multirow[b]{2}{*}{$\begin{array}{l}\text { Odds } \\
\text { Ratio }\end{array}$} & \multicolumn{2}{|c|}{$95 \% \mathrm{CI}$} \\
\hline & & & & Lower & Upper \\
\hline Intercept & $0.40(0.48)$ & 0.69 & & & \\
\hline $\begin{array}{l}\text { Working more than } \\
11 \text { hours }\end{array}$ & $0.88(0.56)$ & 2.46 & 2.41 & 0.80 & 7.24 \\
\hline \multicolumn{6}{|l|}{ Obese vs Healthy } \\
\hline Intercept & $1.37(0.43)$ & 10.36 & & & \\
\hline $\begin{array}{l}\text { Working more than } \\
11 \text { hours }\end{array}$ & $0.27(0.51)$ & 0.28 & 1.31 & 0.49 & 3.53 \\
\hline 45 years and younger & $0.50(0.54)$ & 0.87 & 1.65 & 0.58 & 4.73 \\
\hline \multicolumn{6}{|c|}{ Extremely obese vs healthy } \\
\hline Intercept & $-0.96(0.59)$ & 2.66 & & & \\
\hline $\begin{array}{l}\text { Working more than } \\
11 \text { hours }\end{array}$ & $1.51(0.62)$ & 5.91 & 4.53 & 1.34 & 15.31 \\
\hline 45 years and younger & $1.50(0.61)$ & 6.16 & 4.48 & 1.37 & 14.67 \\
\hline \multicolumn{6}{|c|}{ Extremely obese vs overweight } \\
\hline Intercept & $-1.36(0.53)$ & 6.64 & & & \\
\hline $\begin{array}{l}\text { Working more than } \\
11 \text { hours }\end{array}$ & $0.63(0.52)$ & 1.49 & 1.88 & 0.68 & 5.19 \\
\hline 45 years and younger & $1.40(0.45)$ & 9.71 & 4.04 & 1.68 & 9.71 \\
\hline \multicolumn{6}{|c|}{ Extremely obese vs obese } \\
\hline Intercept & $-2.33(0.47)$ & 24.07 & & & \\
\hline $\begin{array}{l}\text { Working more than } \\
11 \text { hours }\end{array}$ & $1.24(0.45)$ & 7.56 & 3.46 & 1.43 & 8.38 \\
\hline 45 years and younger & $1.00(0.39)$ & 6.53 & 2.72 & 1.26 & 5.86 \\
\hline
\end{tabular}

${ }^{*}$ The only two variables that we examined odds ratios for were the two statistically significant predictor variables. obese, which went against our hypothesis, but the review by Solovieva et $\mathrm{al}^{17}$ also found that younger male workers were more likely to gain weight with increased work hours than older workers.

With $70 \%$ of our sample working on average more than 11 hours daily (or an estimated 55 to 70 hours per week), this is comparable to Sieber et al's ${ }^{20}$ findings of approximately 60 hours of weekly work among their national survey of US drivers. Likewise, our findings of $64.2 \%$ being obese (18.4\% morbidly/extremely obese), are similar to Sieber et al's ${ }^{20}$ findings of nearly $69 \%$ of their sample being obese ( $17 \%$ morbidly/extremely obese). Another recent study of 85,000 long-haul truck drivers found a slightly lower but still high prevalence of obesity $(53.3 \%)$ and extreme obesity $(12.1 \%) .{ }^{42}$ Correspondingly, Luckhaupt et $\mathrm{al}^{18}$ also reported that working more than 40 hours per week was significantly associated with obesity, particularly among men, and that transportation and material moving occupations, such as truck driving, were among the occupations with the highest prevalence ratios.

The findings from this study also support calls from occupational health scholars for workplace interventions to focus on work organization factors, such as long work hours and scheduling practices, in conjunction with individual-level behavior approaches for addressing obesity among employees. ${ }^{18}$ Mirroring calls for integrated approaches in worksite health promotion and occupational safety and health at the national level with the Total Worker Health initiative, ${ }^{43}$ many long-haul truck driver researchers have expressed the need for integrated and comprehensive approaches within the trucking industry. ${ }^{11,20,25,44,45}$ Within the workplace, integrated approaches acknowledge that workplace safety factors and health behaviors are intricately linked and that workplaces can and should simultaneously promote and protect health. The policies and programs incorporated should seek to reduce or eliminate job hazards, such as long work hours, shift work, and job stress, while concurrently promoting healthy individual lifestyles. Meanwhile, workplaces should actively engage their employees and seek to provide a work context that is health supportive, both physically and organizationally. ${ }^{46}$

For truck drivers, this includes the work hours, the way that truckers are compensated (paid by the mile) that incentivizes longer hours, and scheduling practices. ${ }^{11}$ Interventions should involve changes to organizational practices within individual trucking companies, but just as importantly HOS regulations and other public policies need to be continually monitored. Last, it is recognized that this type of approach to trucker health is dependent upon a systems perspective involving multidisciplinary collaboration from multiple stakeholders that should include representation from government regulatory bodies, trucking companies, unions, truck drivers, occupational health researchers, and other policy makers. ${ }^{11}$ Working together and gathering perspectives from each of these individuals and groups can enhance understanding of the long-haul truck driver work organization and identify leverage points for intervening, while also valuing the competitive nature of the industry. ${ }^{11}$

\section{LIMITATIONS}

The study has several limitations. As a result of the crosssectional research design, causal connections cannot be claimed due to any established associations. Furthermore, due to driver selection, as well as the extensive use of prescription medications and the use of drivers' self-reported measures in terms of work hours, schedules, and perceived job stressors, the findings may underrepresent the true scale of the plethora of health-related challenges of long-haul truck drivers in association with their work environment. There is the possibility, as always with self-reported data, that drivers could not be entirely truthful or that they could underreport the number of hours that they work (or scheduling) due to fears from the repercussions of violating industry regulations. Likewise, with some 
drivers on prescriptions medications, there is possibility of the medications having a physiological influence on a driver's body and therefore potentially their BMI; on the contrary, some medications could potentially help drivers maintain their weight and therefore their BMI. As such, the results from this study cannot be generalized to all long-haul truck drivers. Future studies should seek to incorporate larger and more representative samples, health behavior data (physical activity, diet, sleep, etc.), and the collection of longitudinal data as well as the use of biological data (insulin, cholesterol, lipids, etc.). Randomized control trials would be best, but there is the recognition with occupational health studies of the practical, ethical, and legal constraints.

\section{CONCLUSION}

The profession of long-haul truck driving is among the riskiest occupations in the U.S. and as a result has some of the worst health outcomes. Most interventions have focused on individual-behavior changes, ${ }^{25}$ but the findings from this study suggest that longer work hours, specifically, have a major influence on the odds for obesity among this population. As such, the results align with the recent calls at the national level for integrated approaches to worker health and more advanced approaches to understanding and intervening to improve the health of long-haul truck drivers.

\section{ACKNOWLEDGMENTS}

We would like to thank Mr. Tom Liutkus, Vice President of Marketing and Public Relations for Travel Centers of America (TA) and Mr. Jerald Brisson, General Manager of the Whitsett, NC TA truckstop and his staff for their instrumental support for our project and data collection efforts. We also thank the long-haul truck drivers who participated in this study and extend our thanks to our graduate students Kiki Hatzudis (Public Health Education) and Doug Oberlin (Kinesiology) for their invaluable assistance in various phases of data collection.

\section{REFERENCES}

1. Landsbergis PA, Grzywacz JG, LaMontagne AD. Work organization, job insecurity, and occupational health disparities. Am J Ind Med. 2014;57: 495-515.

2. Caruso CC, Bushnell T, Eggerth D, et al. Long working hours, safety, and health: toward a national research agenda. Am J Ind Med. 2006;49: 930-942.

3. Johnson JV, Lipscomb J. Long working hours, occupational health and the changing nature of work organization. Am J Ind Med. 2006;49:921-929.

4. Alterman T, Luckhaupt SE, Dahlhamer JM, et al. Prevalence rates of work organization characteristics among workers in the US: data from the 2010 National Health Interview Survey. Am J Ind Med. 2013;56:647-659.

5. Geiger-Brown JM, Lee CJ, Trinkoff AM. The role of work schedules in occupational health and safety. In: Handbook of Occupational Health and Wellness. New York: Springer Science + Business Media; 2012. 297-322.

6. Caruso CC. Negative impacts of shiftwork and long work hours. Rehabil Nurs. 2014;39:16-25.

7. Wang YC, McPherson K, Marsh T, et al. Health and economic burden of the projected obesity trends in the USA and UK. Lancet. 2011;378:815-825.

8. Hausser JA, Mojzisch A, Niesel M, et al. Ten years on: a review of recent research on the job demand-control (-support) model and psychological wellbeing. Work Stress. 2010;24:1-35

9. Belkic KL, Landsbergis PA, Schnall PL, et al. Is job strain a major source of cardiovascular disease risk. Scand J Work Environ Health. 2004;30 $85-128$.

10. National Institute for Occupational Safety and Health (NIOSH). Occupational Health Supplement. Available at: www.cdc.gov/niosh/topics/nhis/ transocc.html. Accessed February 19, 2016.

11. Apostolopoulos Y, Lemke M, Sönmez S. Risks endemic to long-haul truck trucking in North America: strategies to protect and promote driver wellbeing. New Solut. 2014;24:57-81.

12. Olson R, Anger WK, et al. A new health promotion model for lone workers results of the Safety \& Health Involvement for Truckers (SHIFT) pilot study. J Occup Environ Med. 2009;51:1233-1246.
13. Helmkamp JC, Lincoln JE, Sestito J, et al. Risk factors, health behaviors, and injury among adults employed in the transportation, warehousing, and utilities super sector. Am J Ind Med. 2013;56:556-568.

14. Apostolopoulos Y, Sönmez S, Shattell MM, et al. Health survey of US longhaul truck drivers: work environment, physical health, and healthcare access. Work. 2013;46:113-123.

15. Apostolopoulos Y, Sönmez S, Shattell M. Worksite-induced morbidities of truck drivers in the United States. AAOHN J. 2010;58:285-296.

16. Saltzman GM, Belzer MH. Truck driver occupational safety and health: 2003 conference report and selective literature review. No. DHHS (NIOSH) Publication No. 2007-120. Cincinnati, OH: Department of Health and Human Services, Centers for Disease Control and Prevention; 2007.

17. Soloveiva S, Lalluka T, Virtanen M, et al. Psychosocial factors at work, long work hours, and obesity: a systematic review. Scand J Work Environ Health. 2013;39:241-258.

18. Luckhaupt SE, Cohen MA, Li J, et al. Prevalence of obesity among US workers and associations with occupational factors. Am J Prev Med. 2014;46:237-248.

19. Ogden CL, Carroll MD, Kit BK, et al. Prevalence of childhood and adult obesity in the United States, 2011-2012. JAMA. 2014;311:806-814.

20. Sieber WK, Robinson CF, Birdsey J, et al. Obesity and other risk factors: the national survey of US long-haul truck driver health and injury. Am J Ind Med. 2014;57:615-626.

21. Birdsey J, Alterman T, Li J, et al. Mortality among members of a truck driver trade association. AAOHN. 2010;58:473-480.

22. Robinson CF, Burnett CA. Truck drivers and heart disease in the United States 1979-1990. Am J Ind Med. 2005;47:113-119.

23. Huang TT, Drewnowski A, Kumanyika SK, et al. A systems-oriented multilevel framework for addressing obesity in the $21^{\text {st }}$ century. Prev Chronic Dis. 2009;6(3):A82.

24. Schulte PA, Wagner GR, Ostry A, et al. Work, obesity, and occupational safety and health. Am J Public Health. 2007;97:428.

25. Ng MK, Yousuf B, Bigelow PL, et al. Effectiveness of health promotion programmes for truck drivers: a systematic review. Health Educ $J$ 2014;74:270-286.

26. Rosso GL, Perotto M, Feola M, et al. Investigating obesity among professional drivers: the high risk professional driver study. Am J Ind Med. 2015;58:212-219.

27. Apostolopoulos Y, Sönmez S, Shattell M, et al. Barriers to truck drivers healthy eating: environmental influences and health promotion strategies. $J$ Workplace Behav Health. 2011;26:122-143.

28. Apostolopoulos Y, Shattell M, Sönmez S, et al. Active living in the trucking sector: environmental barriers and health promotion strategies. J Phys Act Health. 2012;9:259-269.

29. Apostolopoulos Y, Sönmez S, Shattell M. Environmental determinants of obesity-associated morbidity risks for truckers. Int $J$ Workplace Health Manag. 2012;5:120-138.

30. Apostolopoulos Y, Lemke M, Sönmez S, et al. The obesogenic environmen of commercial trucking: a worksite environmental audit and implications for systems-based interventions. Am J Health Educ. 2016;47:85-93.

31. Federal Motor Carrier Safety Administration (FMCSA). Hours of Service. Available at: http://www.fmcsa.dot.gov/regulations/hours-of-service. Accessed February 19, 2016.

32. National Heart, Lung, and Blood Institute. Calculate Your Body Mass Index. Available at: http://www.nhlbi.nih.gov/health/educational/lose wt/BMI/bmi calc.htm. Accessed February 19, 2016

33. Fields A. Discovering Statistics Using IBM SPSS Statistics. Thousand Oaks, CA: Sage; 2013.

34. IBM Corp. IBM SPSS Statistics for Windows, Version 23.0. Armonk, NY IBM Corp; 2013.

35. Turner LM, Reed DB. Exercise among commercial truck drivers. AAOHN J. 2011;59:429-436.

36. Ahima RS. Digging deeper into obesity. J Clin Invest. 2011;121:2076-2079.

37. Ramachandrappa S, Farooqi IS. Genetic approaches to understanding human obesity. J Clin Invest. 2011;121:2080-2086.

38. Hege A, Perko M, Johnson A, et al. Surveying the impact of work hours and schedules on commercial motor vehicle driver sleep. Saf Health Work. 2015;6:104-113.

39. Di Milia L, Mummery K. The association between job related factors, short sleep and obesity. Ind Health. 2009;47:363-368.

40. Ko GTC, Chan JCN, Chan AWY, et al. Association between sleeping hours, working hours and obesity in Hong Kong Chinese: the'better health for better Hong Kong' health promotion campaign. Int J Obes. 2006;31:254-260. 
41. Magee CA, Caputi P, Iverson D. Short sleep mediates the association between long work hours and increased body mass index. J Behav Med. 2011;34:83-91.

42. Thiese MS, Effiong AC, Ott U, et al. A clinical trial on weight loss among truck drivers. Int J Occup Environ Med. 2015;6:104-112.

43. Centers for Disease Control and Prevention (CDC). Total Worker Health Available at: http://www.cdc.gov/niosh/TWH/.
44. Lemke MK, Apostolopoulos Y. Introducing a complex systems paradigm. J Ergonomics. 2016;6:152-156.

45. Hege A, Perko M, Apostolopoulos Y, et al. U.S. long-haul truck driver health demands integrated approach. Int J Workplace Health Manag. 2016. In Press.

46. Sorenson G, McLellan D, Dennerlein JT, et al. Integration of health protection and health promotion: rationale, indicators, and metrics. $J$ Occup Environ Med. 2013;55:S12-S18. 